\title{
On a knife's edge of a COVID-19 pandemic: is containment still possible?
}

\section{Raina Maclntyrea,b}

a Biosecurity Research Program, Kirby Institute, Faculty of Medicine, UNSW Sydney, Australia

b Corresponding author: r.macintyre@unsw.edu.au

\section{Article history}

Publication date: March 2020

Citation: Macintyre CR. On a knife's edge of a COVID-19 pandemic: is containment still possible? Public Health Res Pract. 2020;30(1):3012000. https://doi.org/10.17061/phrp3012000

\section{Background}

In 2018, we undertook a training simulation of a pandemic in Sydney, underpinned by mathematical modelling, which went through precisely the issues we are dealing with now in trying to contain the spread of coronavirus disease 2019 (COVID-19) - namely mass quarantine, travel restrictions, stricken cruise ships, mass surveillance, finding enough beds for case isolation and mass contact tracing. ${ }^{1,2}$

Governments everywhere plan for pandemics, because their impact can cause sharp shocks to economies and societies and require a substantial surge in health system capacity. ${ }^{3}$ Severe acute respiratory syndrome coronavirus 2 (SARS-CoV-2), the virus that causes COVID-19, probably emerged in late 2019, and began infecting humans in December 2019. ${ }^{4}$ Only half of the initial cluster of cases had exposure at the Huanan Seafood Wholesale Market in Wuhan. ${ }^{5}$

By mid-January it was clear there was substantial person-to-person transmission. Like SARS-CoV and Middle East respiratory syndrome coronavirus (MERS-CoV), severe infection and mortality is more common in older adults. ${ }^{6}$ Estimates of the reproduction number $\left(R_{0}\right)$, or the number of susceptible people, on average, that an infectious person will infect, have varied between 2 and 7 . The best estimate of $R_{0}$ is 2.2 , based on date of illness onset. ${ }^{5}$ This compares with an $\mathrm{R}_{0}$ of 1.83 for Ebola virus disease, 1.54 for influenza A and 2.9 for SARS. ${ }^{7}$ Most estimates have been based on date of reported cases, not date of symptom onset. The reporting date can result in bias, as illustrated in World Health Organization (WHO) situation reports which show the difference between epidemic curves plotted with symptom onset versus reporting date. ${ }^{8}$

Outbreaks have also occurred in closed settings such as cruise ships, prisons, hospitals and aged care facilities, with growing epidemics in other countries. When sustained transmission was largely localised to China, containment was a feasible goal. However, in Iran and Italy, a high ratio of deaths to cases suggests a substantial proportion of undiagnosed cases and sustained community transmission between people without travel as a risk factor, leading experts to believe a pandemic is likely. ${ }^{9}$ 


\section{Case definition and diagnosis}

The early case definition was severe pneumonia of unknown cause in Wuhan, and as soon as a pathogen was identified and a diagnostic test developed, the case definition changed to only laboratory-confirmed cases as "confirmed cases". By late February, laboratoryconfirmed cases had surged to more than 80000 globally, with $96 \%$ of cases confined to China, and $80 \%$ of those in Hubei province. ${ }^{8}$ On 13 February, the Chinese case definition was changed to include suspected and probable cases based on CT scan or clinical diagnosis, giving a better indication of true disease burden. In the midst of an outbreak, in a heavily affected area like Wuhan, the positive predictive value for COVID-19 of a CT scan may be high. Initial repeated viral testing can be negative in confirmed cases, while a CT scan shows the typical ground glass appearance of pneumonitis. ${ }^{10}$ From an infection control perspective, using chest imaging to get a rapid diagnosis, enabling rapid patient isolation and treatment, is a pragmatic option chosen by clinicians in China because repeated throat swabs were often negative in confirmed cases. ${ }^{10}$ On 20 February there was a reversion back to reporting of laboratory-confirmed cases in Hubei.

\section{Transmission}

SARS was documented to be spread by airborne, droplet and contact routes. The most dramatic example of airborne, long-range transmission was the Amoy Gardens outbreak in Hong Kong. ${ }^{11} \mathrm{~A}$ report of transmission of COVID-19 from floor to floor of a building in Hong Kong has raised questions about long-range aerosol transmission. ${ }^{12}$ SARS-CoV-2 is a respiratory virus, with higher viral loads in the lower respiratory tract compared to the upper, consistent with the possibility of airborne transmission. ${ }^{13}$ Sputum is more likely to be positive than throat swabs, and numerous studies have documented that serial throat swabs may initially be negative in confirmed cases. It can also be found in the faeces, indicating faecal-oral transmission, while not a likely driver of the epidemic, may be possible. Environmental testing at the Huanan seafood market in Wuhan found 33/585 samples from surfaces were positive..$^{14}$ Although cases have occurred in neonates, placenta and breast milk are negative for the virus, suggesting transmission during or after birth. ${ }^{15} \mathrm{It}$ is therefore prudent to assume that transmission may be by contact, droplet and possibly airborne modes.

\section{Asymptomatic and pre- symptomatic transmission}

Symptomatic infection typically has a mild prodrome for 5-9 days before people seek medical attention, resulting in substantial opportunity for community transmission. ${ }^{6}$ A case of an asymptomatic person who transmitted infection has been documented. ${ }^{16}$ This is supported by data that show the viral load detected in an asymptomatic person was similar to that in symptomatic people. ${ }^{17}$ This means asymptomatic cases may be as likely to transmit infection as symptomatic ones. Further, the highest viral load is early in the illness when symptoms are mild. ${ }^{17}$ All of the 565 first Japanese evacuees from Wuhan were tested, whether symptomatic or not, and eight were positive for the virus. Of these, five out of eight were asymptomatic. ${ }^{18}$ In the US, 14 asymptomatic evacuees from the Diamond Princess cruise ship were found to be infected. Japanese researchers estimate that more than $90 \%$ of cases are undetected. ${ }^{18}$ In addition, children and young people may be a reservoir for asymptomatic, mildly symptomatic or pre-symptomatic transmission. In one family cluster, an asymptomatic 10-year-old child had pneumonia on a chest CT scan. ${ }^{13}$

Although paediatric clinical cases are far less common, in Wuhan, nine infants aged younger than 12 months were identified with COVID-19 up to 6 February 2020, with one being asymptomatic. ${ }^{15}$ Given the potential for asymptomatic infection, to prevent sustained community transmission, quarantine is necessary. Further, testing only high-risk travellers or contacts may miss infectious cases. Serological tests are not yet available, but will be helpful for better understanding the extent of asymptomatic transmission. ${ }^{19}$

\section{The role of border control, quarantine and isolation}

Travel restrictions, quarantine of well people who have been in contact with a case or are otherwise high risk for becoming ill, and isolation of people with infection (whether symptomatic or not) are key interventions for disease control. Travel is the major vector for transmission of infections globally, so border control measures, including restriction of travel (lockdown), will reduce transmission. The lockdown of Wuhan on 23 January should and does show impact within the incubation period of 2 weeks, by 7 February as shown in Figure 1. It is also expected to result in more impact outside Hubei than in Hubei itself, confirmed in Figure 1. The unprecedented travel restrictions impacting almost half of the entire population of China have reduced the spread of the virus, both in Hubei and in other parts of China. The epidemic peaked on 5 February in Hubei and 3 February in the rest of China, and has been declining since. However, there may be resurgence of cases after 23 February, being 2 weeks after the end of the holiday period. Consistent with this, there is continuing disease activity in Hubei, while the rest of China remains low incidence.

Similarly, the epidemic curves provided by WHO of cases outside China show a peak in early February and early decline in global cases within one incubation period after lockdown, confirming that many countries have seen 
Figure 1. COVID-19 epidemic curve, Hubei and the rest of China, 31 Dec 2019-1 March 2020a

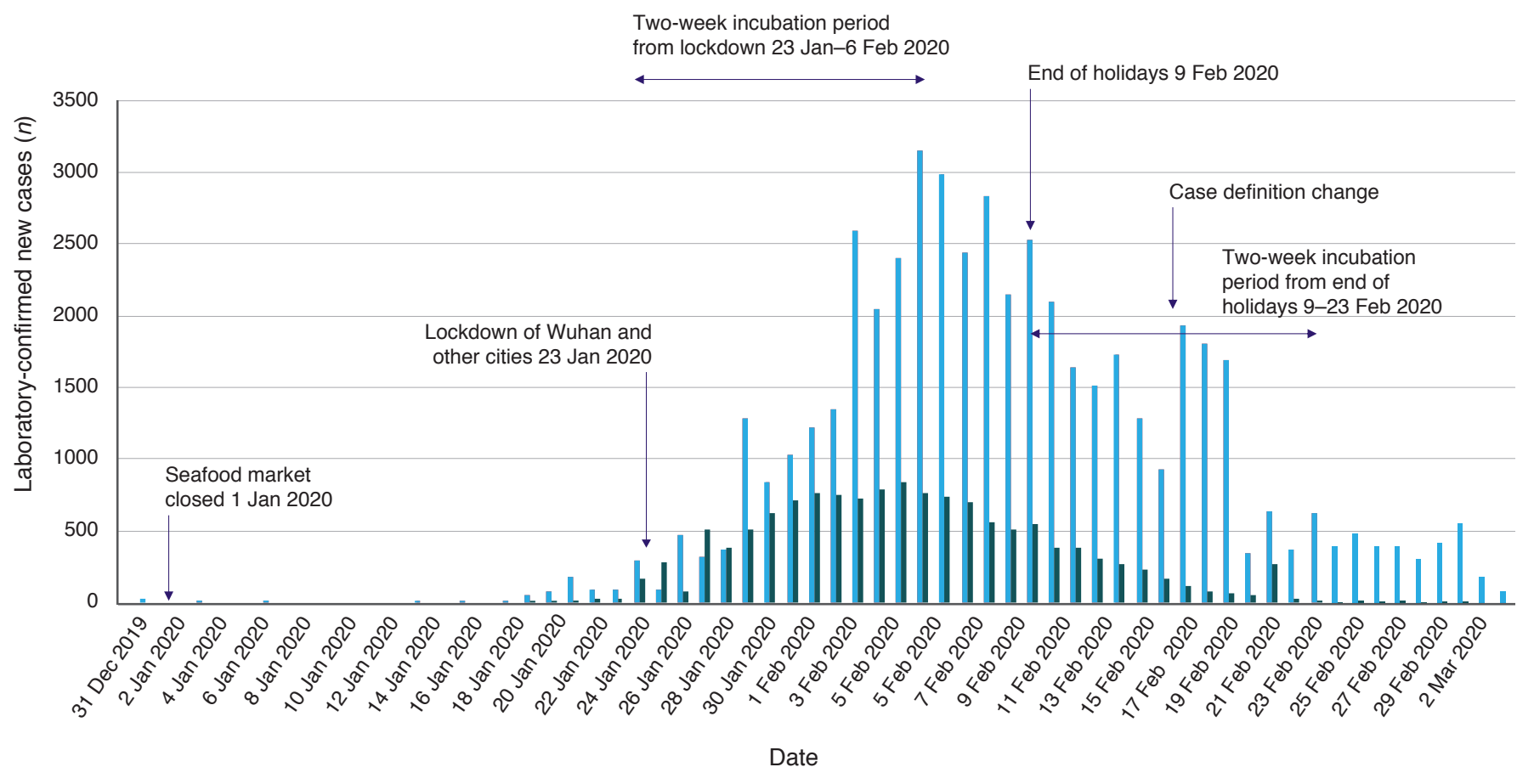

Hube

China (other)

a Data sourced from media reports, ProMED-Mail and WHO situation reports (available since 21 Jan 2020)

the benefit of the lockdown in China, especially those that implemented their own travel restrictions. ${ }^{20}$ However, by late February, cases began to surge outside of China, reflecting missed cases, poor testing capacity and delayed control measures in many countries.

\section{Cruise ships}

While China and some other nation states have tightly controlled travel and movement of people, cruise ships carry passengers from many countries and do not fall neatly into state jurisdictions. The largest outbreak outside of China by mid-February was on a cruise ship. The Japanese screened passengers on the Diamond Princess cruise ship and found that a high percentage positive tests were in asymptomatic people. The evacuation of passengers to their home countries is complex, as it involves two stages (from ship to land and from land to air) and thus more potential points for transmission. Treatment and isolation capacity for cases is also a problem, with Japan initially treating patients in their onshore hospitals, but later electing to keep mildly symptomatic cases on board the ship.

A cruise ship berthed in Sydney Harbour with more than 500 COVID-19 cases of a severity requiring hospital admission would immediately stress our health system, if 500 isolation beds and 25 intensive care unit (ICU) beds were required. Unless we develop clear cross-national management plans for treatment, isolation, quarantine and evacuation of global citizens, cruise ships may be the weak link that results in sustained community transmission in other countries. Advice to Australians to avoid cruises in the Asia-Western Pacific region at this time may be prudent.

\section{Rationale for trying to 'stamp it out'}

If we did nothing, we would face a larger and more prolonged epidemic that would cause greater stress on our health system than the 2009 pandemic, which had a much lower case fatality rate of $<1 \%$ compared with an estimated 2.3\% for COVID-19.21,22 Our capacity for ICU and isolation beds may rapidly be exhausted, as well as stockpiles of personal protective equipment and other supplies. ${ }^{23}$ We have shown in a modelled smallpox epidemic in Sydney - involving comparable control measures to what we face now with COVID-19 - that requirements for masks and respirators for health workers would exceed 30 million if the epidemic continued for 6 months or more. ${ }^{23}$

With an ageing population and a more severe illness in older people, Australia may see a proportionately greater morbidity and mortality impact than China. As such, we should persist with all feasible measures for as long as possible. Travel bans and quarantine are proven interventions, and especially critical for infections with pre-symptomatic or asymptomatic transmission. ${ }^{7}$ The public health goal is to prevent the epidemic becoming sustained in Australia, or if that is not possible, to delay it and reduce the total number of cases using all available interventions. Delay provides time for preparedness, expansion of quarantine and isolation capacity, and shortens the time to availability of a vaccine. 
Figure 2. COVID-19 epidemic curve in Australia and potential transmission events, Jan-Mar 2020ª

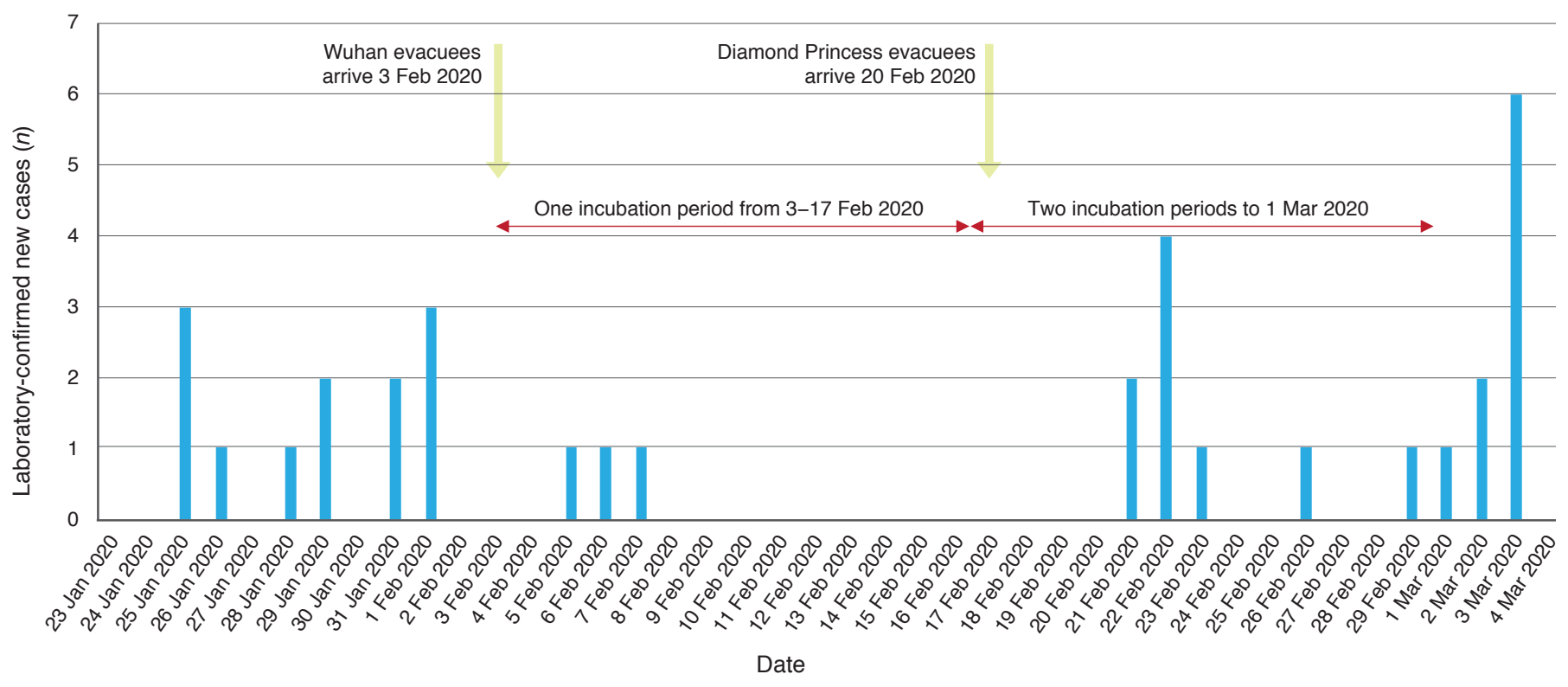

a Data sourced from media reports and WHO situation reports

However, travel bans are not sustainable indefinitely because of our close economic ties with China and other countries. Supplies of foods, essential medicines, computers, car parts and innumerable other products from China are affected globally. Countries everywhere will need to make choices between the economic and public health consequences of COVID-19. A surge of cases worldwide may occur when travel bans are lifted, and we need to be prepared for the impacts on the health system. Sites where young people congregate such as schools, universities, sporting and entertainment venues would be sites of more intense transmission, and an outbreak in an aged care facility has already occurred in Australia. The use of community volunteers and alternative sites for contact quarantine and case isolation may need to be considered during a pandemic.

Meanwhile, epidemics in other countries outside of China continue to grow, with a surge in cases in South Korea and likely a large proportion of undetected cases in Iran and Italy. The occurrence of cases with no travel or contact history in the US, and now Australia, suggests sustained community transmission is occurring. The occurrence of these cases in Australia is two incubation periods after the first evacuation from Wuhan, as shown in Figure 2. Most countries only tested symptomatic evacuees throughout January and much of February, with Japan the first country to test all evacuees. ${ }^{18}$ The lesson learnt from this is that all high-risk evacuees, contacts and return travellers should be tested, or missed asymptomatic cases may cause undetected chains of transmission in the community. Failures in case detection and loss of epidemic control in other countries increases the likelihood of a pandemic, which appears to already be upon us.

\section{Peer review and provenance}

Internally peer reviewed, commissioned.

\section{Competing interests}

The Kirby Institute has received an investigator-driven grant from Sanofi for work in influenza. This is not related to COVID-19, however Sanofi is developing a COVID-19 vaccine.

\section{Author contributions}

CRM is the sole author.

\section{References}

1. Maclntyre C, Heslop D, Nand D, Schramm C, Butel M, Rawlinson W, et al. Exercise Mataika: white paper on response to a smallpox bioterrorism release in the Pacific. Global Biosecurity. 2019;1(1):91-105.

2. Maclntyre C, Costantino V, Mohanty B, Nand D, Kunasekaran M, Heslop D. Epidemic size, duration and vaccine stockpiling following a large-scale attack with smallpox. Global Biosecurity. 2019;1(1):74-81.

3. Maclntyre R. The risk of selective investment in downstream pandemic planning. Global Biosecurity. 2019;1(2):85-90.

4. Xu X, Chen P, Wang J, Feng J, Zhou H, Li X, et al. Evolution of the novel coronavirus from the ongoing Wuhan outbreak and modeling of its spike protein for risk of human transmission. Sci China Life Sci. 2020:1-4. 
5. Li Q, Guan X, Wu P, Wang X, Zhou L, Tong Y, et al. Early transmission dynamics in Wuhan, China, of novel coronavirus-infected pneumonia. N Engl J Med. 2020; Epub 2020 Jan 29.

6. Wang D, Hu B, Hu C, Zhu F, Liu X, Zhang J, et al. Clinical characteristics of 138 hospitalized patients with 2019 novel coronavirus-infected pneumonia in Wuhan, China. JAMA. 2020; Epub 2020 Feb 7.

7. Peak CM, Childs LM, Grad YH, Buckee CO. Comparing nonpharmaceutical interventions for containing emerging epidemics. Proc Natl Acad Sci U S A. 2017; 114(15):4023-8.

8. World Health Organisation. Coronavirus disease 2019 (COVID-19) situation report - 38. Geneva: WHO; 2020 [cited 2020 Mar 3]. Available from: www.who.int/docs/ default-source/coronaviruse/situation-reports/20200227sitrep-38-covid-19.pdf?sfvrsn=9f98940c_29.

9. Gates B. Responding to covid-19 - a once-in-a-century pandemic? N Engl J Med. 2020; Epub 2020 Feb 28.

10. Xie X, Zhong Z, Zhao W, Zheng C, Wang F, Liu J. Chest CT for typical 2019-nCoV pneumonia: relationship to negative RT-PCR testing. Radiology. 2020:200343.

11. McKinney KR, Gong YY, Lewis TG. Environmental transmission of SARS at Amoy Gardens. J Environ Health. 2006;68(9):26-30; quiz 51-2.

12. Regan $\mathrm{H}$. How can the coronavirus spread through bathroom pipes? Experts are investigating in Hong Kong. CNN; 2020 Feb 12; [cited 2020 Feb 20]. Available from: edition.cnn.com/2020/02/12/asia/hong-kong-coronaviruspipes-intl-hnk/index.html

13. Chan JF-W, Yuan S, Kok K-H, To KK-W, Chu H, Yang J, et al. A familial cluster of pneumonia associated with the 2019 novel coronavirus indicating person-toperson transmission: a study of a family cluster. Lancet. 2020;395(10223):514-523.

14. Xia H. China detects large quantity of novel coronavirus at Wuhan seafood market. Xinhua News Agency; 2020 Jan 26 [cited 2020 Feb 20]. Available from: www. xinhuanet.com/english/2020-01/27/c_138735677.htm
15. Wei M, Yuan J, Liu Y, Fu T, Yu X, Zhang Z-J. Novel coronavirus infection in hospitalized infants under 1 year of age in China. JAMA. 2020; Epub 2020 Feb 14.

16. Bai Y, Yao L, Wei T, Tian F, Jin DY, Chen L, Wang M. Presumed asymptomatic carrier transmission of COVID-19. JAMA. 2020; Epub 2020 Feb 21.

17. Zou L, Ruan F, Huang M, Liang L, Huang $\mathrm{H}$, Hong Z, et al. SARS-CoV-2 viral load in upper respiratory specimens of infected patients. N Engl J Med. 2020; Epub 2020 Feb 19.

18. Nishiura H, Kobayashi T, Yang Y, Hayashi K, Miyama T, Kinoshita $\mathrm{R}$, et al. The rate of underascertainment of novel coronavirus (2019-nCoV) infection: estimation using Japanese passengers data on evacuation flights. J Clin Med. 2020;9(2).

19. Heymann DL, Shindo N, WHO Scientific and Technical Advisory Group for Infectious Hazards. COVID-19: what is next for public health? Lancet. 2020; 395(10224):542-45.

20. World Health Organisation. Coronavirus disease 2019 (COVID-19) situation report - 29. Geneva: WHO; 2020 [cited 2020 Feb 20]. Available from: www.who.int/docs/ default-source/coronaviruse/situation-reports/20200218sitrep-29-covid-19.pdf?sfvrsn=6262de9e_2

21. McCallum L, Partridge J. Epidemiological characteristics of the influenza $A(\mathrm{H} 1 \mathrm{~N} 1) 2009$ pandemic in the Western Pacific Region. Western Pac Surveill Response J. 2010;1(1):5-11.

22. Wu Z, McGoogan JM. Characteristics of and important lessons from the coronavirus disease 2019 (COVID-19) outbreak in China. 2020; Epub 2020 Feb 24.

23. Maclntyre CR, Costantino V, Kunasekaran MP. Health system capacity in Sydney, Australia in the event of a biological attack with smallpox. PLOS One. 2019;14(6):e0217704

\section{Copyright: (c)}

(c) 2020 MacIntyre. This article is licensed under the Creative Commons Attribution-NonCommercial-ShareAlike 4.0 International Licence, which allows others to redistribute, adapt and share this work non-commercially provided they attribute the work and any adapted version of it is distributed under the same Creative Commons licence terms. See: www.creativecommons.org/licenses/by-nc-sa/4.0/ 